\title{
Conceptual Profile of Chemistry: A Framework for Enriching Thinking and Action in Chemistry Education
}

\author{
Melquesedeque Freire ${ }^{1}$, Vicente Talanquer $^{2}$ and Edenia Amaral ${ }^{3}$ \\ ${ }^{1}$ Instituto de Química, Universidade Federal do Rio Grande do Norte, Natal RN, Brazil \\ Corresponding at melquimico@yahoo.com.br \\ ${ }^{2}$ Univesity of Arizona, Tucson AZ, USA \\ ${ }^{3}$ Universidade Federal Rural de Pernambuco, Recife PE, Brazil
}

\begin{abstract}
Understanding the nature of chemical thinking and action, as well as their application and impact on our world should be central goals of chemistry education at all educational levels. However, traditional school chemistry is still mostly focused on having students learn the body of declarative knowledge built over the years in the discipline. Achieving changes in curriculum and teaching practices in this context remains a challenging task. Studies in the history and philosophy of the discipline suggest that chemistry has unique characteristics that need to be recognized and considered in chemistry education. Many of these studies point to a pluralism in the discipline, and in the understanding of and about chemistry, that should be characterized and incorporated into our educational models. In this essay, we have attempted to build such a characterization using conceptual profiles theory to propose a framework that can be used to enrich and support the thinking and action of chemistry teachers at all educational levels.
\end{abstract}

Keywords: Chemistry, Chemistry Education, Nature of Chemistry

\section{What does the philosophy of chemistry tell us about the nature of the discipline and its teaching?}

Chemistry as a science has a pluralistic constitution that can be characterized along epistemological, ontological, methodological, and axiological dimensions (Bachelard, 1932; Ribeiro \& Pereira, 2013; Schummer, 2014). In particular, the discipline has a dual character as it has features of both a natural science and a technology. The goals of the chemical enterprise are inextricably linked to basic human aims and pursuits, and these relationships have profound consequences on the ways of reasoning, methodology, and values of the discipline (Sjöström, 2007). The diverse social, political, economic, environmental, and ethical implications of chemical thinking and action have been analyzed in several studies in the history and philosophy of chemistry (BensaudeVincent \& Simon, 2008).

Philosophers of chemistry have identified distinctive epistemological and sociological characteristics of chemistry and of its role in society that shape its pluralistic identity (Scerri \& McIntyre, 1997, Baird, Scerri \& McIntyre, 2006, Bensaude-Vincent, 2009). Chemistry has been portrayed, for example, as a science of substances and processes (Stein 2004; Earley 2004, 2006), a science of material transformations (Van Brakel 1997), a central science (Schummer, 1998), an academic and industrial science (Laszlo, 2006), and a practical science (Müürsepp, 2016). Given the interrelationship between economic, industrial, and academic contexts, as well as among several actors, such as teachers, researchers, and engineers, Sjöström (2006) has claimed that chemistry is a post-industrial and post-academic science. The symbiotic relationship between the science and the industry has shaped the self-image of chemists 
(Laszlo, 2006), and transformed the practice of chemistry into a technoscience which combines scientific and technological aims and practices (Chamizo, 2013).

Results from studies on the philosophy of chemistry have important implications for chemistry education (Erduran, 2001, 2009; Erduran \& Scerri, 2002, Erduran \& Mugaloglu, 2013, Lombardi \& Labarca, 2007). Examples of these types of studies include analyses and discussions of instances of reductionism in traditional chemistry curricula (Erduran, 2005), interpretations of students' misconceptions from a philosophical perspective (Kidenemariam, Atagana \& Engida, 2013), and reflections about the nature of chemical concepts (Laszlo, 1999), and laws and theories (Erduran, 2007). These types of studies have sparked discussions about the nature and focus of traditional chemistry curricula, pointing to the need for new educational models that take a more humanistic perspective (Sjöström \& Talanquer, 2014), and that more authentically represent the aims, practices, and benefits, costs, and risks of engaging in chemical thinking and action (Talanquer \& Pollard, 2010; Talanquer, 2013a).

Historical, philosophical, and sociological studies of chemistry highlight critical aspects of the discipline that teachers and instructors must recognize to avoid presenting a mono-faceted view of the discipline. This knowledge can help educators problematize their understanding of and about chemistry, its role in society, and its teaching (Sjöström \& Talanquer, 2014), empowering them to introduce changes in their practice (Erduran, Bravo \& Naaman, 2007). On the other hand, chemistry education studies point to the struggles that students face to understand central concepts and ideas in the discipline, and reveal instructional strategies that better foster meaningful learning (Talanquer, 2018). Many chemistry teachers, however, are unaware of these different studies or do not know how to productively incorporate them into their teaching. In this contribution, we propose that the analysis and discussion of different zones in a conceptual profile of chemistry that points to different ways of thinking and speaking about the discipline can serve as a framework for engaging teachers with such rich and diverse bodies of work. In particular, we seek to answer the question: how does the analysis of different zones in a conceptual profile of chemistry can enrich and support the thinking and action of chemistry teachers? The word "chemistry" is used in different ways in the academic, industrial, and daily-life arenas. The analysis of the variety of meanings attributed to it creates opportunities for critically reflecting about aims and practices in chemistry education from different perspectives. Engaging teachers in such reflections is necessary if we are to escape traditional approaches to chemistry education that present the discipline as a static, aseptic, and unproblematic body of knowledge.

This essay relies on results from an empirical study on the conceptual profile of chemistry (Freire, 2017) summarized in section 3. However, our contribution focuses on the theoretical analysis of how engaging teachers in discussions about each of the zones in this conceptual profile can enrich their thinking and educational practice. Our framework provides an avenue for engaging teachers in the analysis of the nature of chemical knowledge, thinking, and action from philosophical, historical, and sociological perspectives, while highlighting their implications for chemistry teaching and learning. The various zones in the conceptual profile of chemistry direct teachers' attention to different facets of chemistry education that can be used to guide and support the development of the types of authentic learning experiences that modern educational standards advocate (NRC, 2013). A central premise of our work is that a better 
understanding of the nature of chemical knowledge, thinking, and action will support teachers' engagement in reformed practices.

\section{Conceptual profiles theory}

The theory of conceptual profiles was introduced in the science education research literature by Eduardo Mortimer more than twenty years ago (Mortimer, 1995). Inspired by Bachelard's ideas about epistemological profiles (Bachelard, 1968), the theory was initially proposed as an alternative to existing models of conceptual change. However, over the years the conceptual profiles theory has evolved through the incorporation of sociocultural perspectives and pragmatist philosophy (Mortimer \& El-Hani, 2014).

The conceptual profile theory proposes that people can exhibit different ways of seeing and representing the world, which manifest and are used in different contexts. These different modes of thinking are interwoven with different ways of speaking. The theory recognizes the coexistence in every individual of two or more meanings for the same word or concept, which are accessed by a person depending on the context. (Tulviste 1991; Mortimer \& El-Hani, 2014). The theory acknowledges that word meanings are often polysemous, both in science and in everyday language.

Conceptual profiles can be understood as models of the diversity of modes of thinking available to individuals from a given sociocultural context to use in different domains of their experience. Each of these different modes of thinking corresponds to a "zone" in the conceptual profile of a concept. Each of the zones offers a way of understanding a concept that is different from that of the other zones, and it corresponds to different mediational means, theories, and languages that represent the world in their own way. Each zone in the conceptual profile of a concept is stabilized by ontological, epistemological, and axiological commitments that support meaning making about the concept (Mortimer \& El-Hani, 2014).

To illustrate the idea of different zones in a conceptual profile, consider the different ways of thinking and talking about the concept of "heat" in diverse contexts (Mortimer $\&$ El-Hani, 2014). At home, we can think or speak of heat as a fluid-like substance that can be contained (e.g., close the oven so that heat does not escape) or we can think and speak of it as a property of an object that is opposite to being cold (e.g., that stove is really hot). At school, heat can be used to refer to the transfer of energy that takes place when objects with different temperature are in contact (e.g., energy in the form of heat will be transferred from the hot to the cold object until their temperatures are the same.) The recognition of and reflection on the different ways heat is conceptualized in various contexts help us develop a deeper understanding of this scientific concept. Similarly, analysis of the different zones in a conceptual profile of chemistry can enrich our understanding of chemical knowledge, thinking, and action.

To date, several authors have built the conceptual profiles of different scientific concepts such as atom, physical states of matter (Mortimer, 1995, 2000), chemical reaction (Solsona, Izquierdo \& De Jong, 2003), heat (Amaral \& Mortimer, 2001), entropy and spontaneity (Amaral, Mortimer \& Scott, 2014), substance (Silva \& Amaral, 2013; Amaral, Silva \& Sabino, 2018), molecule (Mortimer \& Amaral, 2014) and life (Coutinho, El-Hani \& Mortimer, 2014). In the following section, we summarize the results of a study focused on developing the conceptual profile of "chemistry" which characterizes different modes of thinking and ways of speaking about chemistry in different domains (Freire, 2017; Freire \& Amaral, 2018). Then, we discuss how this 
conceptual profile can be used as a tool to guide reflection about central issues in chemistry education.

\section{A conceptual profile of chemistry}

A conceptual profile of chemistry was built by the first author of this contribution based on the examination of data obtained from diverse sources, including published studies on the history and philosophy of chemistry, literature on students' misconceptions in the discipline, and actual ways of speaking about chemistry gathered through questionnaires and classroom video-recordings (Freire, 2017). This latter empirical component involved nine undergraduate students enrolled in a course for preservice chemistry teachers in a Brazilian university. Data were collected as part of these students' participation in a 4-day activity focused on the philosophy of chemistry. Transcriptions of videos from the classroom were analyzed using a framework developed by Mortimer and Scott (2003) that, among others, considers the following categories of analysis: teaching purposes, class content, and teacher's interventions.

The multisource analysis described above led to the identification of epistemological, ontological, and axiological commitments that support different ways of thinking and talking about chemistry. In particular, six different zones were identified in the conceptual profile of chemistry labeled: monist, aversive, epistemic, pragmatic, processual, and attractive. A brief description of the mode of thinking about chemistry characteristic of each zone in the conceptual profile is presented in Table 1, together with representative examples of their manifestation in students' talk as observed in the collected data.

[Table 1 near here]

To better illustrate how different modes of thinking about chemistry manifested in the actual speeches of preservice teachers involved in the original study, consider the following episode extracted from an activity in which the preservice teachers (PT) and their instructor (I) are discussing the meaning of sentences about chemistry from conventional textbooks:

1. I: Let's go, who is the first to speak?

2. PT4: That first there... (in reference to the sentence "chemistry is the study of matter and its changes") it's from the textbook, isn't it? Because it is quite how I think (...), considering the experimental aspects too, the reactions...

3. PT6: This last... (he reads it aloud) chemistry is responsible for environmental contamination. I don't agree with it, because I do not see it being the chemistry IN ITSELF but the way how chemistry is used.

4. I: Okay, anybody else?

5. PT1: This fifth (in reference to the sentence "Chemistry is just applied Physics") also is totally... (he shakes his head in disagreement)

6. I: But physicists like to say that: we study from subatomic particles to the universe, all galaxies. Physics can handle all this; everything is inside Physics.

7. PT3: In the same way mathematicians say that everything is mathematics.

8. PT4: Everything is chemistry.

9. PT3: And chemistry as a science, it is not so ancient, isn't it? Chemistry as a science... regarding chemistry as a science I think is not so ancient...

10. I: Yeah, it depends on what you mean by chemistry/ 
11. PT3: Chemistry is present since the beginning of things, isn't it? If you believe that all was created (he points to the space around him), that it had a Creator, so chemistry was present since that moment. However, if you think of it as a science, like mathematics, then I think it's less ancient, isn't it?

This episode shows the preservice teachers and their instructor engaged in a negotiation of meanings through discursive interactions that points to different zones in the conceptual profile of chemistry, including the monist, aversive, epistemic and processual zones. For instance, ways of speaking representative of the epistemic zone emerged in turns 2 and 9, when PT4 referred to textbook content and PT3 speaks of chemistry as a science. On the other hand, aversive zone emerges as PT6 referred to chemistry as a transforming agent that can be used with negative consequences (turn 3 ). In turns 6,7 and 8, the preservice teachers expressed ways of speaking related to the monist zone, when discussing the idea that mathematics, physics, and chemistry are everywhere. In turn 11, PT3 simultaneously expressed different modes of thinking about chemistry. First, he suggested a theological conception, in which chemistry is related to an entity that is present in all things (monist zone); secondly, he mentioned chemistry as a science (epistemic zone); and, finally, the processual zone seemed to emerge when he suggested the existence of processes and transformations taking place since the beginning of the universe. The different ways of speaking evidenced the heterogeneity of thinking when preservice teachers discuss on chemistry.

In this paper, we advance the idea that the analysis and discussion of the different zones in the conceptual profile of chemistry creates opportunities to think about diverse facets of chemistry education and enrich teachers' thinking and practice. The different zones in the conceptual profile of chemistry provide a framework that can be used to enrich chemistry teachers' perspectives about educational goals, student learning, and productive practices. In the following section, we present and discuss the specific ways in which each zone of the conceptual profile could motivate and guide discussions and reflections about chemistry education. Analysis and discussion related to a given zone may be more relevant to some teachers than others, depending on the educational level in which they teach, the nature of the students with whom they work, and the educational goals of the curriculum that they follow.

\section{Using the conceptual profile of chemistry as a framework for reflection in chemistry education}

Traditional chemistry education often depicts the discipline as a collection of topics that need to be covered by teachers and understood by students (Eilks, Rauch, Ralle \& Holfstein, 2013; Talanquer, 2013a). However, philosophical, historical, and sociological studies on the nature of chemistry suggest new ways of conceptualizing chemistry education that can make it more authentic, meaningful, and relevant to students.

Given the pluralism of chemistry, one can expect chemistry knowledge to be rich, complex, and multifaceted. In this regard, Talanquer (2013b) has described and discussed ten facets that reveal the multidimensional nature of chemistry as a school subject. This author makes explicit the rich and multilayered nature of chemical knowledge and practices, and invites chemical educators to reflect on this issue. The ten facets characterized in that study refer to the following aspects of chemical thinking and action: big ideas, essential questions, cross-cutting concepts, conceptual dimensions, 
knowledge types, dimensional scales, modes of reasoning, contextual issues, historical views, and philosophical considerations.

In this contribution, we argue that the different zones in the conceptual profile of chemistry provide useful contexts in which different facets of chemical knowledge could be explored and discussed. Figure 1 provides a blueprint of the different aspects of chemistry that may be associated with the different zones in the profile. In this figure, chemistry is presented as a concept in the center surrounded by the six different zones described before. Fundamental questions in chemistry education closely associated with each zone are also presented in this blueprint. Analysis and discussion of ideas related to each zone can be used to highlight diverse aspects of chemistry education. The proposed framework provides an articulated set of modes for both thinking about chemistry and characterizing the discipline as chemistry teachers engage in lesson planning and implementation, and in the development of educational resources.

[Figure 1 near here]

\subsection{The monist zone}

The idea that "chemistry" can be found all around us seems to be well established among chemists and chemistry educators. This viewpoint is often expressed in textbooks, scientific papers, educational policy documents, and popular science magazines. This idea seeks to draw attention to the importance of learning chemistry since it is usually accompanied by the implicit message that chemistry is inescapable as the material world emerges from and is sustained by chemical substances and processes (Bensaude-Vincent \& Simon, 2008).

The analysis and discussion of a monist perspective of chemistry could serve as springboard to elicit teachers' ideas about the subject and challenge them to reflect more deeply about different views on the nature of chemistry. Teachers could engage in discussion guided by questions such as: Is the material world equivalent to chemistry? Does chemistry exist independently of human thought, experience, and values? Is chemistry an object of study, the knowledge that results from that study, or the actual practice of studying the material world?

Discussions about the monist zone in the conceptual profile of chemistry offer the opportunity for teachers to analyze how views about the nature of chemistry have changed over the years, and compare and contrast academic, philosophical, and sociological perspectives of the discipline. Teachers should confront questions about the absolute versus tentative nature of chemical and scientific knowledge, and recognize the extent to which certain views of chemistry contribute to (de)humanize it (Abd-ElKhalick, 2013). This would be particularly important for educators who seek to teach chemistry in context or with a socio-humanistic perspective.

Discussions about the nature of chemistry could be combined with analyses of the nature of science in general. Learning about how scientific knowledge is generated and about how science is influenced by social and historical processes have become central goals in science education standards across the world. Literature on the nature of science for science education advocates the use of history and philosophy of science to promote scientific and technological literacy (Dagher \& Erduran, 2016). A critical analysis of the monist perspective of chemistry could help challenge naïve views of science in which scientific knowledge is seen as literal representation of reality independent of human consciousness. It can help teachers become aware of other 
perspectives that suggest that there is no eternal essence to chemistry to be traced back across the centuries but, instead, the chemical enterprise can be better characterized as a cultural production historically situated (Bensaude-Vincent \& Simon, 2008).

As part of the proposed discussions related to the monist zone in the conceptual profile of chemistry, teachers could explore chemistry curricula and teaching practices that seek to make more explicit the genesis of chemical knowledge and ideas (Eilks, Rauch, Ralle \& Holfstein, 2013). In several of these approaches, students are given opportunities to explore significant events in the history of chemistry to better understand the conditions in which they took place, as well as their goals and scientific and social relevance (Izquierdo-Aymerich, 2013; Chamizo, 2014).

\subsection{The epistemic zone}

One of the most common images of chemistry derives from people's experiences in traditional chemistry classrooms. In this view, chemistry is seen as a difficult subject full with abstract ideas and algorithmic procedures (Salta \& Tzougraki, 2004). For many students and teachers, chemistry is about balancing chemical equations, solving stoichiometry problems, building electron configurations, writing Lewis structures, or skillfully manipulating chemical symbols. This common epistemic perspective of chemistry sees the discipline as a collection of isolated concepts, skills, and procedures, rather than as a complex and powerful way of thinking to make sense, predict, and control real phenomena and experiences in our world (Talanquer \& Pollard, 2010).

Chemistry teachers need to critically analyze traditional epistemic views about chemistry and chemistry learning. These discussions can create opportunities for them to explore alternative perspectives about school chemistry that seek to portray the discipline in more authentic ways and actively engage students in the construction of relevant and meaningful understandings (Talanquer \& Pollard, 2010; Eilks, Rauch, Ralle \& Holfstein, 2013; Cooper \& Klimkowsky, 2013). These alternative educational approaches emphasize the need for educators to reflect on the essential questions they want their students to explore, and to identify the central (or big) ideas and practices they want them to understand and develop. In recent years, several documents have been published that make explicit these core ideas and practices; teachers should be asked to reflect upon them and learn how use them to guide their practice (Talanquer, 2013b, 2016; NRC, 2013; Cooper, Posey \& Underwood, 2017).

Reflection on the epistemic zone in the conceptual profile of chemistry should support chemistry teachers in making decisions about what to teach, assess, or investigate at different educational levels. Challenging educators' views about chemistry learning may enrich their understanding of the discipline and help them adopt new perspectives on how to design and implement meaningful learning experiences for their students (Erduran, Bravo \& Naaman, 2007). In this process, teachers should also be invited to think more deeply about both the structure of chemistry knowledge and the difficulties that learners may face to construct it.

Several authors have presented models for the structure of chemistry knowledge that point to different forms, levels, or types in which such knowledge can be organized. One of the most well-known models was proposed by Johnstone (1991) who identified three major levels of chemical thought: the macro, submicro, and symbolic levels. This model has been extremely productive in guiding reflection, research, development, and practice in chemistry education (Gilbert \& Treagust, 2009). Over the years, this model 
has been adopted and adapted in various ways, enriching it but also adding complexity in its interpretation (Talanquer, 2011). Some authors have added other levels to Johnstone's original model to include a humanistic dimension (Mahaffy, 2004; Sjöström $\&$ Talanquer, 2014). Other authors have sought to clarify the connections between the different levels to make more explicit the difficulties that students frequently experience when operating at and between them (Taber, 2002, 2013).

Existing analyses of chemical thinking and action reveal many complexities that educators need to understand and reflect upon to better support student learning. Chemical knowledge can be characterized along multiple levels or scales (macro to submicro), dimensions (structure, energy, and time), and knowledge types (experiences, models, and visualizations) (Jensen, 1998; Talanquer, 2011). Chemical reasoning may manifest and be applied in different ways: model-based, case-based, and rule-based, depending on the nature of the task (Kraft, Strickland \& Bhattacharyya, 2010; Talanquer, 2013b). Chemical rationales presented in explanations and arguments may be phenomenological, mechanical, or structural (Talanquer, 2018). Chemical action is sustained by a variety of practices that integrate knowledge and reasoning across types, levels, and dimensions (Talanquer, 2016). Chemistry teachers need to be confronted with this complexity to challenge and problematize their views about chemistry and chemistry learning.

Given the complexity of chemical knowledge, it is not strange that students' intuitive implicit assumptions about the nature of chemical substances and processes are often not aligned with those that support chemical thinking (Talanquer, 2006; Taber \& Garcia-Franco, 2011). These mismatch leads to the many misconceptions that students express about a variety of chemical concepts (Taber, 2002; Kind, 2004; Barke, Hazri \& Yitbarek, 2008). Teachers need to compare and contrast the fundamental assumptions that support intuitive versus chemical reasoning if they are to develop a better understanding of the challenges that students face in learning chemistry.

\subsection{The processual zone}

Within the processual zone, chemistry is seen as transformation of matter that alters its qualities and results in the disappearance of some materials and the creation of new "stuff." The processes or mechanisms through which chemical transformations take place are often unknown or ignored, and it is thus not strange for people to link chemical changes to magic. The analysis and discussion of this view of chemistry can thus serve as the basis for reflection on the importance of engaging chemistry students in exploring diverse chemical processes and generating models that represent reaction mechanisms at the submicroscopic level.

Chemical scientists and engineers generate and apply a variety of models to describe, explain, predict, and control chemical processes, Designing, testing, evaluating, and revising models of substances and their transformations are core chemical practices (Justi \& Gilbert, 2002, Erduran \& Scerri, 2002). Understanding the nature of chemical models is critical for understanding both the nature of chemistry and the big ideas in the discipline (Erduran \& Duschl, 2004). This understanding demands discussion of ontological and epistemological question about chemical models, as well as analyses of how these types of representations support reasoning in the discipline (Bensaude-Vincent, 2009). Justi and Gilbert (2002) highlight the importance of teachers engaging in the analysis of the scope and limitations of models as they engage in modelling themselves, and when they work with students in the classroom. Discussing 
the processual view of chemistry can serve as a springboard to engage teachers in such analyses, and in the discussion of the nature of chemical models and their connection with the "real" world.

Many models of chemical reactions are mechanistic in nature. Chemical educators need to understand the basic tenets of mechanistic reasoning (Russ, Scherr, Hammer \& Mikeska, 2008) and reflect on how to scaffold this way of thinking in the chemistry classroom. Existing research in chemistry education shows that many students are unable to generate mechanistic explanations about basic chemical processes (Cooper, Kouyoumdjian \& Underwood, 2016), relying instead on rules and other heuristics to make predictions, build explanations, and generate arguments (Talanquer, 2014). Adopting a mechanistic approach in the exploration and analysis of chemical processes in the classroom creates opportunities for knowledge integration through the application of cross-cutting concepts such as cause and effect, structure-property relationships, and stability and change (NRC, 2013). Teachers should reflect on how to use these crosscutting concepts to provide students with reasoning tools that they can apply in different contexts to make sense of chemical transformations in a unified manner.

The construction of chemical models often takes advantage of a specialized chemical symbology that supports representation and meaning making (Hoffman \& Laszlo, 1991). Understanding chemical models and the explanations derived from their application requires knowledge about words, symbols, signs, and other tools of the chemistry language (Taber, 2009). Consequently, the discussion about the role of models in chemistry can be expanded to include reflection on how a focus on modelling in chemistry education can facilitate the introduction of chemical language in productive manners, rather than as a mere labeling system that needs to be memorized. These discussions could focus on the analysis of teaching strategies that successfully integrate the development of chemical symbology with modelling and representational practices (Cooper, Stieff \& De Sutter, 2017).

\subsection{The pragmatic zone}

Many chemistry teachers have a rather academic perspective of the discipline that may be limiting when trying to give relevance to what is being learned in the classroom and to connect learning objectives with the interests of students, the communities they live in, or with their own motivations as teachers or researcher. Discussion of views of chemistry as a practical endeavor can thus help enrich teachers' personal perspectives and challenge their beliefs about the goals of chemistry education.

Throughout its history, the chemical enterprise has been characterized by its strong practical concerns (Knight, 1992, Bensaude-Vincent \& Simon, 2008). The modern chemical industry has maintained such a focus, guided in its purposes by human needs, practical considerations, economic ambitions, and environmental concerns. Theoretical research and industrial interests are often intertwined in chemical research and practice, giving chemistry the character of a technoscience that merges the pursuit of scientific knowledge with technological goals (Chamizo, 2013). Schummer (1999) suggests that common criteria used to distinguish between science and technology fail when applied to chemistry. Other factors, such as conflicts of interest, research financing, patents and other types of intellectual property, as well as political and economic considerations need to be taken into account when characterizing chemical activities (Sjöström, 2006, 2007). Chemistry educators should engage in the analysis and discussion of the pragmatic view of the discipline if they are expected to escape the confines of the 
narrow vision of the field that they typically develop through their university studies. Engaging teachers and instructors in discussion of social, economic, political, and ethical aspects supports recent calls from science educators who advocate for science courses that problematize the construction of scientific knowledge and the role of science in modern societies (Dagher \& Erduran, 2016).

Reflecting on the pragmatic view of chemistry should help educators recognize that chemical thinking and action is not only focused on explaining and predicting the properties of matter, but also on designing, implementing, and evaluating methods and strategies to analyze, synthesize, and transform chemical substances in real settings. Chemical analysis and synthesis are central activities in chemistry with major social, economic, political, ethical, environmental, and ecological ramifications (Hoffmann; 1995; Schummer, 1997, 1998). Chemical knowledge is often developed for practical purposes involving the characterization and production of targeted types of matter to design, create, and control desired outcomes (Talanquer, 2016). Chemical thinking and action rely on common scientific practices, but also on engineering practices such as designing methods and products (NRC, 2013). Modern chemical practices pose new questions about the nature of chemistry, such as how chemical synthesis has been deeply transformed by the use of computer-based methods or how nanotechnology seems to challenge traditional views of synthesis, making it difficult to distinguish between 'pure' and 'applied' chemical research (Bensaude-Vincent $\&$ Simon, 2008).

The production and consumption of chemical products have benefits, costs, and risks in various dimensions (Sjöström \& Talanquer, 2014). Chemical educators should be challenged to devise strategies for engaging students in benefit-cost-risk analyses of the many chemical products they consume and of the chemical processes they benefit from. Using relevant problems and phenomena situated in realistic contexts to anchor instruction does not only motivate students to learn, but also helps them develop more meaningful understandings. Curricula and instruction that involves students in collaborative activity that authentically represents chemical practice can successfully merge the academic goal of having students understand fundamental ideas in the discipline with the practical aim of enabling them to make sense of major issues facing modern societies and make informed decisions in a complex world (Bulte, Westbroek, De Jong \& Pilot, 2006).

\subsection{The aversive zone}

In modern times, a widespread hostility towards chemistry has led people to often ascribe a negative connotation to the word "chemical," typically used to refer to manmade and potentially dangerous materials. This chemophobia can be linked to an intuitive human tendency to favor the "natural" (Rozin, 2005), but also stems from major pollution and health problems for which some chemical industries are to blame (Laszlo, 2006; Bensaude-Vincent \& Simon, 2008).

The public image of chemistry is a construction with a long history and can be characterized as a complex social and cultural phenomenon with deep and complex roots (Schummer, Bensaude-Vincent, \& Tiggelen, 2007). In the book Chemistry - The impure science, Bensaude-Vincent and Simon (2008) characterize chemistry as a discipline wedded to a global industry that has been involved in the production of toxic substances that have indelibly marked our planet. This marriage between the science and its industry paints chemistry as a polluting agent that contaminates the soil, poisons our water, and pollutes the air we breathe. Additionally, modern chemistry has not fully 
escaped its alchemical heritage which is linked in the popular mind to poisons, chemical warfare, and sorcery (Schummer, Bensaude-Vincent, \& Tiggelen, 2007). It is thus not strange that common stereotypes of mad scientists involve individuals dressed in white lab gowns, holding fuming flasks filled with substances that can destroy the world (Weingart, 2006).

Chemistry teachers need to analyze the roots of negative views of the discipline and reflect on how to guide students to develop a more critical and balanced perspective on the benefits, costs, and risks of chemical products and activities. These types of analyses and discussions can support the development of teachers that can take a Bildungoriented approach towards chemistry education, seeking to problematize the content by considering social, economic, political, ethical, environmental, and ecological issues (Sjöström, 2013; Sjöström, Eilks, \& Zuin, 2016). Moving beyond building superficial daily-life connections to traditional topics in the curriculum, this approach seeks to develop critical, action-competent citizens who can understand the complex world they live in, make informed decisions in their daily lives, and engage in social-political activity that promotes sustainable action and development (Vilches \& Gil-Pérez, 2013; Sjöström \& Talanquer, 2014).

Through the analysis of the aversive zone in the conceptual profile of chemistry, teachers can be introduced to educational models centered on the analyses of socioscientific issues (SSI) as anchors for the development of fundamental understandings in the discipline. SSI approaches create opportunities for students to confront their personal beliefs with existing scientific understandings on an issue, taking into consideration moral principles and elements of virtue that guide the societies they live in (Zeidler, Sadler, Simmons \& Howes, 2005). In order for students to develop a more nuanced view of chemistry and its impact on our world, they need to be given opportunities to grapple with multiple perspectives to problems that inherently involve discrepant viewpoints and information, consider moral and ethical issues, while applying core disciplinary concepts, ideas, and practices to make sense of phenomena and inform their decisions.

\subsection{The attractive zone}

The attractive zone in the conceptual profile of chemistry captures a common way of speaking in everyday language that suggests the existence of "chemistry" between some people. In this perspective, chemistry is seen as affinity or successful interaction and the concept moves to the biological, psychological, and sociological planes. Historically, within the alchemical tradition, the material, biological, psychological, and spiritual spheres were not separated by sharp boundaries (Read, 1995). For alchemists, transforming substances involved transforming the body, soul, and spirit of matter but also their own. Over time, boundaries between different areas of human knowledge and experience grew sharper, but nowadays are becoming more diffuse. Discussions related to the attractive zone create opportunities to reflect on the connections that exists between chemistry and other scientific disciplines and forms of knowing, from indigenous views about nature to common sense ways of thinking.

The complexity of the scientific enterprise and the growing interrelationships among its participants has led to both specialization and integration into new interdisciplinary fields. In this environment, Sjöström (2006) has suggested that classical views of chemistry have shifted from an academic mode to a more application-oriented mode characterized by emerging subfields and metafields that cross the border between the 
sciences and between science and technology, following a problem-oriented and interdisciplinary approach (e.g., materials chemistry, environmental chemistry). Chemistry has become a central science through its conceptual foundations and analytical and synthetic tools, sustaining thought and action in diverse fields, including the environment, health, agriculture, cosmology, materials, molecular biology, and nanotechnology.

The relations between chemistry and other disciplines have been a topic of interest to philosophers of chemistry for a long time (Scerri \& McIntyre, 1997, Van Brakel, 2006). As suggested by Bensaude-Vincent \& Simon (2008), some of these relationships are affecting the identity of the discipline. In particular, the integration of chemistry, biology, and nanotechnology is reshaping research agendas, redirecting economic resources and educational programs away from traditional subdisciplines in chemistry (e.g. organic, analytical, physical).

The increasing focus on interdisciplinary research and development projects is fueling new efforts to reform science education (DOE, 2016). Current reform projects seek to more actively engage students in the analysis of complex problems and situations, adopting multiple perspectives and integrating different types of knowledge and skills. Chemistry educators should have opportunities to analyze and reflect on existing initiatives to reform STEM education that are likely to transform the teaching of their discipline and its role in the school curriculum.

Discussions about the attractive zone in the conceptual profile of chemistry could also open opportunities to analyze and reflect on other forms of knowing about the chemical world that are typically not considered formal chemistry. These may include discussions about common sense of thinking about materials and their transformations expressed in informal settings, to the chemistry-related knowledge and practices from different cultures and ethnic groups.

\section{Final Comments}

Over the past 50 years, studies in the history, philosophy, and sociology of chemistry, together with educational research in chemistry teaching and learning, have generated many important insights about the nature of chemical knowledge, thinking, and action and the struggles that students face to develop meaningful understandings in the discipline. Chemistry teachers, however, are often unaware of these findings. In this contribution, we propose that the analysis of different zones in a conceptual profile of chemistry could serve as an avenue and framework for engaging teachers with such rich and diverse bodies of work. This essay highlights critical areas of knowledge and reflection in chemistry education that can support teachers in the design implementation, and evaluation of curricula, lesson plans, assessments, and educational resources to support student learning.

Recognizing and critically reflecting on different ways of speaking about chemistry creates opportunities for teachers to reconceptualize the discipline and the ways they engage students in chemistry learning. Educational change and innovation are difficult in part due to entrenched beliefs about the nature of the subject matter, the way people learn, and traditional teaching practices. Our framework relies on the analysis of common ways of speaking about chemistry to challenge those beliefs and introduce alternative perspectives on the nature of chemistry that call into question conventional 
views about chemistry teaching and learning. The success of modern calls to transform science and chemistry education to engage students in more authentic learning experiences depends on our ability to meaningfully affect the ways in which teachers conceptualize the nature of chemistry and what it means to learn the discipline.

Given the breadth of chemical knowledge and activity, one may think that discussions and reflections related to one zone in the conceptual profile of chemistry may be more relevant to some educators than others. We believe, however, that chemistry teachers at all educational levels should engage in the reflections and discussions we have described for each of the different zones in the conceptual profile of chemistry. Otherwise, we are likely to perpetuate visions of chemistry education in which discussions about social, environmental, and ethical issues, or active engagement in modeling practices, are only seen as relevant and useful for students at the secondary school level while college chemistry courses remain focused on the aseptic presentation of chemical knowledge. Chemistry education at all levels should aspire to engage students in authentic activity that simulates the complexities of chemical thinking and action as advocated in current educational standards and certification requirements. Chemistry teachers will be in a better position to decide what learning experiences are most appropriate in a particular context if they have a broad understanding of the diverse and complex nature of chemical thinking and action.

Although we have described needed reflections and discussions in chemistry education using the different zones in the conceptual profile of chemistry as organizers, we can foresee analyses that cut across various zones. For example, reflections on the role of new biochemical techniques used to modify genetic material and develop transgenic products could be situated in the pragmatic, aversive, and attractive zones. Or reflections on the types of chemical rationales used in chemistry to make sense of the likelihood of chemical processes (Talanquer, 2018) may overlap the epistemic and processual zones. The different zones characterized in this essay define diverse lenses for analysis that can be applied in independent or interrelated manners.

Throughout this essay we have presented examples of the implications that reflections and discussions associated with the different zones in the conceptual profile of chemistry have for chemistry teaching and learning. Overall, these implications point to the urgent need to complexify traditional views of chemistry education to create more authentic learning experiences for all students. Our suggested framework for reflection is based on the conviction that chemistry educators at all levels need to think about their discipline from multiple perspectives, including not only the academic and cognitive points of view, but also historical, philosophical, social, political, economic, moral, ethical, environmental, and ecological considerations. Recognizing the uniqueness and complexity of chemical thinking and action, as well as its impact on our world, is of fundamental importance if we want to educate individuals that can make sense of the complex world they live in, and are prepared to make informed decisions about socioscientific issues that can dramatically affect human societies and our planet.

\section{References}

Abd-El-Khalick, F. (2013). Teaching with and about nature of science, and science teacher knowledge domains. Science \& Education, 22(9), 2087-2107. 
Amaral, E. M. R., \& Mortimer, E. F. (2001). Uma proposta de perfil conceitual para o conceito de calor [A conceptual profile proposal for the concept of heat]. Revista Brasileira de Pesquisa em Educação em Ciências, 1(3), 5-18.

Amaral, E. M. R., Mortimer, E. F., \& Scott, P. (2014). A conceptual profile of entropy and spontaneity: characterising modes of thinking and ways of speaking. In E. F. Mortimer \& C. N. El-Hani (Eds.), Conceptual profiles: A theory of teaching and learning scientific concepts (pp. 201-234). Dordrecht: Springer.

Amaral, E. M. R., Silva, J. R. R. T., \& Sabino, J. D. (2018). Analysing processes of conceptualization for students in lessons on substance from the emergence of conceptual profiles zones. Chemistry Education Research and Practice, 19(4), 1010-1028.

Bachelard, G. (1932). Le pluralisme cohérent de la chimie moderne [The Coherent Pluralism of Modern Chemistry]. Paris: Vrin.

Bachelard, G. (1968). The philosophy of no. New York, NY: The Orion Press.

Baird, D., Scerri, E., \& McIntyre, L. (Eds.). (2006). Philosophy of chemistry: Synthesis of a new discipline. Dordrecht: Springer.

Barke, H. D., Hazri, A., \& Yitbarek, S. (2008). Misconceptions in chemistry: Addressing perceptions in chemical education. Berlin: Springer Verlag.

Bensaude-Vincent, B., \& Simon, J. (2008). Chemistry: the impure science. London: Imperial College Press.

Bensaude-Vincent, B. (2009). The chemists' style of thinking. Ber Wissenschaftsgesch, 32(4), 365-378.

Bulte, A. M. W., Westbroek, H. B., De Jong, O., \& Pilot, A. (2006). A research approach to designing chemistry education using authentic practices as contexts. International Journal of Science Education, 28(10), 1063-1086.

Chamizo, J. A. (2013). Technochemistry: One of the chemists' ways of knowing. Foundations of Chemistry, 15(2), 157-170.

Chamizo, J. A. (2014). The role of instruments in three chemical' revolutions. Science \& Education, 23(4), 955-982.

Cooper, M., \& Klymkowsky, M. (2013). Chemistry, Life, the Universe, and Everything: A new approach to General Chemistry, and a model for curriculum reform. Journal of Chemical Education, 90(9), 1116-1122.

Cooper, M. M., Kouyoumdjian, H., \& Underwood, S. M. (2016). Investigating students' reasoning about acid-base reactions. Journal of Chemical Education, 93(10), 17031712.

Cooper, M. M., Posey, L. A., \& Underwood, S. M. (2017). Core ideas and topics: Building up or drilling down? Journal of Chemical Education, 4(5) 541-548.

Cooper, M. M., Stieff, M., \& De Sutter, D. (2017). Sketching the invisible to predict the visible: From drawing to modeling in chemistry. Topics in Cognitive Science, 9(4), 902-920.

Coutinho, F. A., El-Hani, C. N., \& Mortimer, E. F. (2014). Building a profile for the biological concept of life. In E. F. Mortimer \& C. N. El-Hani (Eds.), Conceptual 
profiles: A theory of teaching and learning scientific concepts (pp. 115-142). Dordrecht: Springer.

Department of Education (DOE) (2016). STEM 2026: A vision for innovation in STEM Education. Washington DC, US Department of Education.

Dagher, Z. R. \& Erduran, S. (2016). Reconceptualizing the nature of science for science education: Why does it matter? Science \& Education, 25(1), 147-164.

Earley, J. E. (2004). Would introductory chemistry courses work better with a new philosophical basis? Foundations of Chemistry, 6(3), 137-160.

Earley, J. E. (2006). Some philosophical influences on Ilya Prigogine's statistical mechanics. Foundations of Chemistry, 8(3), 271-283.

Eilks, I., Rauch, F., Ralle, B., \& Holfstein, A. (2013). How to allocate the chemistry curriculum between science and society. In I. Eilks \& A. Holfstein (Eds.), Teaching chemistry - A studybook: A practical guide and textbook for student teachers, teacher trainees and teachers (pp. 1-36). Rotterdam: Sense Publishers.

Erduran, S. (2001). Philosophy of Chemistry: An emerging field with implications for chemistry education. Science \& Education, 10(6), 581-593.

Erduran, S. (2005). Applying the philosophical concept of reduction to the chemistry of water: implications for chemical education. Science \& Education, 14(2), 161-171.

Erduran, S. (2007). Breaking the law: Promoting domain-specificity in chemical education in the context of arguing about the periodic law. Foundations of Chemistry, 9(3), 247-263.

Erduran, S. (2009). Beyond philosophical confusion: Establishing the role of philosophy of chemistry in chemical education research. Journal of Baltic Science Education, 8(1), 5-14.

Erduran, S., \& Scerri, E. (2002). The nature of chemical knowledge and chemical education. In J. K. Gilbert, O. De Jong, R. Justi, D. F. Treagust, \& J. H. van Driel (Eds.), Chemical education: Towards research-based practice (pp. 7-27). Dordrecht: Kluwer.

Erduran, S., \& Duschl, R. (2004). Interdisciplinary characterization of models and the nature of chemical knowledge in the classroom. Studies in Science Education, 40(1), 105-138.

Erduran, S., Bravo, A. A., \& Naaman, R. M. (2007). Developing epistemologically empowered teachers: Examining the role of philosophy of chemistry in teacher education. Science \& Education, 16, 975-989.

Erduran, S., \& Mugaloglu, E. (2013). Interactions of economics of science and science education: Investigating the implications for science teaching and learning. Science \& Education, 22(10), 2405-2425.

Freire, M. S. (2017). Perfil conceitual de Química: Contribuições para uma análise da natureza da química e do seu ensino [Conceptual Profile of Chemistry: Contributions for an analysis of Nature of Chemistry and Chemistry Education] (Doctoral dissertation). Universidade Federal Rural de Pernambuco, Recife, Brazil.

Freire, M. S. \& Amaral, E. M. R. (2018). Analyzing conceptions On chemistry: Proposal for a Conceptual Profile. In Finlayson, O. E., McLoughlin, E., Erduran, 
S., \& Childs, P. (Eds.), Electronic Proceedings of the ESERA 2017 Conference. Research, Practice and Collaboration in Science Education, Part 1 (co-ed. Odilla Finlayson \& Roser Pinto), (pp. 100-108). Dublin, Ireland: Dublin City University.

Gilbert, J. K.. \& Treagust, D. (Eds.) (2009). Multiple representations in chemical education. The Netherlands: Springer.

Hoffmann, R. (1995). The same and not the same. New York, NY: Columbia University Press.

Hoffmann, R., \& Laszlo, P. (1991). Representation in Chemistry. Angewandte Chemie, 30(1), 1-16.

Izquierdo-Aymerich, M. (2013). School chemistry: An historical and philosophical approach. Science \& Education, 22(7), 1633-1653.

Jensen, W. B. (1998). Logic, history, and the chemistry textbook. I. Does chemistry have a logical structure? Journal of Chemical Education, 75(6), 679-687.

Johnstone. A. H. (1991). Why is science difficult to learn? Things are seldom like they seem. Journal of Computer Assisted Learning, 7(2), 75-83.

Justi, R., \& Gilbert, J. K. (2002). Modelling, teachers' views on the nature of modelling, and implications for the education of modellers. International Journal of Science Education, 24(4), 369-387.

Kidenemariam, D. A., Atagana, H. I., \& Engida, T. (2013). The place of philosophy of chemistry in reducing chemical misconceptions. African Journal of Chemical Education, 3(2), 106-117.

Kind, V. (2004). Beyond appearances: students' misconceptions about basic chemical ideas (2nd ed.). London: Royal Society of Chemistry.

Knight, D. (1992). Ideas in chemistry: a history of the science. London: The Athlone Press.

Kraft, A., Strickland A. M., \& Bhattacharyya G. (2010). Reasonable reasoning: Multivariate problem-solving in organic chemistry. Chemistry Education Research and Practice, 11(4), 281-292.

Laszlo, P. (1999). Circulation of concepts. Foundations of Chemistry, 1(3), 225-239.

Laszlo, P. (2006). On the self-image of chemists, 1950-2000. HYLE: International Journal for Philosophy of Chemistry, 12(1), 99-130.

Lombardi, O., \& Labarca M. (2007). The philosophy of chemistry as a new resource for chemistry education, Journal of Chemical Education, 84(1), 187-192.

Mahaffy, P. (2004). The future shape of chemistry education. Chemistry Education: Research and Practice, 5(3), 229-245.

Mortimer, E. F. (1995). Conceptual change or conceptual profile change? Science \& Education, 4(3), 268-283.

Mortimer, E. F. (2000). Linguagem e Formação de Conceitos no Ensino de Ciências. [Language and Formations of Concepts in Science Education]. Belo Horizonte: Editora da UFMG. 
Mortimer, E. F., \& Amaral, L. O. F. (2014). Contributions of the Sociocultural Domain to Build a Conceptual Profile Model for Molecule and Molecular Structure. In Mortimer, E. F., \& El-Hani, C. N. (eds) Conceptual profiles: A theory of teaching and learning scientific concepts. Dordrecht: Springer. 103-114.

Mortimer, E. F., \& El-Hani, C. N. (Eds.). (2014). Conceptual profiles: A theory of teaching and learning scientific concepts. Dordrecht: Springer.

Mortimer, E. F. \& Scott, P. (2003). Meaning making in secondary science classrooms. Maidenhead: Open University Press.

Müürsepp, P. (2016). Chemistry as a practical science (Edward Caldin Revisited). Foundations of Chemistry, 18(2), 113-123.

National Research Council (NRC). (2013). The Next Generation Science Standards. Washington DC: National Academy Press.

Read, J. (1995). From Alchemy to Chemistry. New York: Dover.

Ribeiro, M. A. P., \& Pereira, D. C. (2013). Constitutive pluralism of chemistry: thought planning, curriculum, epistemological and didactic orientations. Science \& Education, 22(7), 1809-1837.

Rozin, P. (2005). The meaning of natural. Psychological Science, 16(8), 652-658.

Russ, R. S., Scherr, R. E., Hammer, D., \& Mikeska, J. (2008). Recognizing mechanistic reasoning in student scientific inquiry: A framework for discourse analysis developed from philosophy of science. Science Education, 92(3), 499-525.

Salta, K., \& Tzougraki, C. (2004). Attitudes toward chemistry among 11th grade students in high schools in Greece. Science Education, 88(4), 535-547.

Scerri, E., \& McIntyre, L. (1997). The case for the philosophy of Chemistry. Synthese 111(3), 213-232.

Schummer, J. (1997). Scientometric Studies on Chemistry I: the exponential growth of chemical substances, 1800-1995. Scientometrics, 39(1), 107-123.

Schummer, J. (1998). The chemical core of chemistry, I: A conceptual approach. HYLE: International Journal for Philosophy of Chemistry, 4(2), 129-162.

Schummer, J. (1999). Coping with the growth of chemical knowledge - Challenges for chemistry documentation, education, and working chemists. Educación Química, 10(1), 92-101.

Schummer, J., Bensaude-Vincent, B., \& Tiggelen, V. (2007). The public image of Chemistry. Singapore: World Scientific.

Schummer, J. (2014). The methodological pluralism of Chemistry and its philosophical implications. In E. Scerri \& L. McIntyre (Eds.), Philosophy of Chemistry: review a current discipline. Dordrecht: Springer.

Silva, J. R. R. T. \& Amaral, E. M. R. (2013). Proposta de um perfil conceitual para substância [Proposal of a Conceptual Profile for Substance]. Revista Brasileira de Pesquisa em Educação em Ciências, 13(3), 53-72.

Sjöström, J. (2006). Beyond classical chemistry: Subfields and metafields of the molecular sciences. Chemistry International, 28, 9-15. 
Sjöström, J. (2007). The discourse of chemistry (and beyond). HYLE: International Journal for Philosophy of Chemistry, 13(2), 83-97.

Sjöström J. (2013). Towards Bildung-oriented chemistry education. Science \& Education, 22(7), 1873-1890.

Sjöström, J. \& Talanquer, V. (2014). Humanizing chemistry education: From simple contextualization to multifaceted problematization. Journal of Chemical Education. 91(8), 1125-1131.

Sjöström, J., Eilks, I., \& Zuin, V. G. (2016). Towards eco-reflexive science education. Science \& Education, 25, 321-341.

Solsona, N., Izquierdo, M., \& De Jong, O. (2003). Exploring the development of students' conceptual profiles of chemical change. International Journal of Science Education, 25(1), 3-12.

Stein, R. L. (2004). Towards a process philosophy of chemistry. HYLE: International Journal for Philosophy of Chemistry, 10(1), 5-22.

Taber, K. S. (2002). Chemical misconceptions-Prevention, diagnosis and cure: vol. I: theoretical background. London: Royal Society of Chemistry.

Taber, K. S. (2009). Learning at the symbolic level. In J. K. Gilbert \& D. F. Treagust (Eds.), Multiple representations in chemical education (pp. 75-108). Springer: Dordrecht.

Taber, K. S. (2013). Revisiting the chemistry triplet: drawing upon the nature of chemical knowledge and the psychology of learning to inform chemistry education. Chemistry Education Research and Practice, 14(2), 156-168.

Taber, K. S., \& García-Franco, A. (2010). Learning processes in chemistry: drawing upon cognitive resources to learn about the particulate structure of matter. The Journal of the Learning Sciences, 19(1), 99-142.

Talanquer, V. (2006). Commonsense chemistry: A model for understanding students' alternative conceptions. Journal of Chemical Education, 83(5), 811-816.

Talanquer, V. (2011). Macro, Submicro, and Symbolic: The many faces of the chemistry “triplet”. International Journal of Science Education, 33(2), 179-195.

Talanquer, V. (2013a). School chemistry: the need for transgression. Science \& Education, 22(7), 1757-1773.

Talanquer, V. (2013b). Chemistry education: Ten facets to shape us. Journal of Chemical Education, 90, 832-838.

Talanquer, V. (2014). Chemistry education: Ten heuristics to tame. Journal of Chemical Education, 91(8), 1091-1097.

Talanquer, V. (2016). Central ideas in chemistry: An alternative perspective. Journal of Chemical Education, 93(1), 3-8.

Talanquer, V. (2018). Chemical rationales: another triplet for chemical thinking. International Journal of Science Education, 40(15), 1874-1890.

Talanquer, V., \& Pollard, J. (2010). Let's teach how we think instead of what we know. Chemistry Education Research and Practice, 11, 74-83. 
Tulviste, P. (1991). Cultural-historical development of verbal thinking: A psychological study. Commack, NY: Nova Science Publishers.

Van Brakel, J. (1997). Chemistry as the science of the transformation of substances. Synthese, 111(3), 253-282.

Van Brakel, J. (2006). The philosophy of chemistry: From infancy toward maturity. In D. Baird, E. Scerri \& L. McIntyre (Eds.), Philosophy of Chemistry: Synthesis of a new discipline. Dordrecht: Kluwer.

Vilches, A., \& Gil-Pérez, D. (2013). Creating a sustainable future: Some philosophical and educational considerations for chemistry teaching. Science \& Education, 22(7), $1857-1872$.

Weingart, P. (2006). Chemists and their craft in fiction film. Hyle - International Journal for Philosophy of Chemistry, 12(1), 31-44.

Zeidler, D. L., Sadler, T. D., Simmons, M. L., \& Howes, E. V. (2005). Beyond STS: A research-based framework for socioscientific issues education. Science Education, 89(3), 357-377. 